\title{
Potential future fisheries yields in shelf waters: a model study of the effects of climate change and ocean acidification
}

\author{
S. M. van Leeuwen, W. F. Le Quesne, and E. R. Parker \\ Centre for Environment, Fisheries and Aquaculture Science (Cefas), Pakefield Road, Lowestoft, NR33 0HT, UK \\ Correspondence to: S. M. van Leeuwen (sonja.vanleeuwen@cefas.co.uk)
}

Received: 30 April 2015 - Published in Biogeosciences Discuss.: 1 July 2015

Revised: 14 December 2015 - Accepted: 6 January 2016 - Published: 21 January 2016

\begin{abstract}
We applied a coupled marine water column model to three sites in the North Sea. The three sites represent different hydrodynamic regimes and are thus representative of a wider area. The model consists of a hydro-biogeochemical model (GOTM-ERSEM-BFM) coupled one way upwards to a size-structured model representing pelagic predators and detritivores (Blanchard et al., 2009). Thus, bottom-up pressures like changing abiotic environment (climate change, chemical cycling) will have an impact on fish biomass across the size spectrum. Here, we studied three different impacts of future conditions on fish yield: climatic impacts (medium emission scenario), abiotic ocean acidification impacts (reduced pelagic nitrification), and biotic ocean acidification impacts (reduced detritivore growth rate). The three impacts were studied separately and combined, and results showed that sites within different hydrodynamic regimes can respond very differently. The seasonally stratified site showed an increase in fish yields (occurring in winter and spring), with acidification effects of the same order of magnitude as climatic effects. The permanently mixed site also showed an increase in fish yield (increase in summer, decrease in winter), due to climatic effects moderated by acidification impacts. The third site, which is characterised by large interannual variability in thermal stratification duration, showed a decline in fish yields (occurring in winter) due to decline in the benthic system which forms an important carbon pathway at this site. All sites displayed a shift towards a more pelagic-oriented system.
\end{abstract}

\section{Introduction}

Responsible management of marine resources has to take into account the different pressures operating on the marine system, like fishing pressures, changing climatic conditions, and eutrophication issues. Ocean acidification, the increased uptake of $\mathrm{CO}_{2}$ by the marine environment due to elevated levels of atmospheric $\mathrm{CO}_{2}$ (Doney et al., 2009; Gattuso et al., 2011), is a recent addition to this list, but it has the potential for widespread impact on the marine food web (see e.g. Fabry et al., 2008; Kroeker et al., 2010). Research into ocean acidification effects have focussed largely on individual species and changes to their local environment, without considering the wider ecosystem and possible societal impact (Doney et al., 2009; Le Quesne and Pinnegar, 2012). The combined effects of direct (species level) and indirect (abiotic environment level) changes due to ocean acidification across the food web remain unknown. However, these relative impacts need to be understood in order to support effective and targeted environmental management. This study applies a modelling approach to examine the potential higherlevel effects of the impacts of climate change and ocean acidification on marine ecosystems.

There is a growing body of evidence that ocean acidification can have a range of direct effects on marine organisms and processes (Fabry et al., 2008; Kroeker et al., 2010, 2013). However, evidence of a physiological response to ocean acidification does not necessarily imply an ecological- or systemlevel response to ocean acidification (Le Quesne and Pinnegar, 2012). Potential system-level responses of ocean acidification are most likely to occur where there is a clear relationship between the effect of ocean acidification and a system-level process such as nutrient recycling or energy fluxes. 
In this study we examine potential higher- and lowertrophic-level effects of ocean acidification with the potential to affect ecosystem-wide dynamics by emulating two effects that have been demonstrated to occur in multiple independent studies. These effects that are examined are a decrease in microbial nitrification (Beman et al., 2011; Huesemann et al., 2002; Hutchins et al., 2009) and decline in growth efficiency in benthic calcifiers due to the increased energetic cost of calcification (Andersson et al., 2011). A decline in nitrification could reduce the supply of oxidised nitrogen, the nitrogen substrates that supports new primary production, leading to a shift in the phytoplankton community. An increase in the energetic cost of calcification could reduce growth efficiency and hence reduce trophic transfer efficiency of benthic calcifiers.

Here, modelling tools are used to provide a first indication of single and combined effects of direct and indirect impacts of climate change and ocean acidification on a marine food web. As such, these model experiments form a sensitivity study into effects of different pressures. The main objective is to estimate the relative impact of both changing climatic conditions and ocean acidification effects (direct and indirect effects) across a marine food web. To this end, a coupled ecosystem model was applied in selected locations around the North Sea (north-western European continental shelf) which described the abiotic and biotic environment up to commercial-size fish level. Impacts of future climatic conditions are compared with ocean acidification driven impacts on pelagic nitrogen cycling and growth efficiency of benthic organisms.

\section{The applied ecosystem model}

The model simulating the physical processes, chemical cycling, and lower-trophic-level biological communities is GOTM-ERSEM-BFM. This water column model was developed in a joint effort by the Cefas (UK) and NIOZ (the Netherlands) institutes with the specific aim to represent shallow shelf seas in detail. Higher trophic levels are simulated using a size-structured model.

\subsection{Lower trophic levels}

Water column hydrodynamics were simulated using the GOTM model (General Ocean Turbulence Model; see www. gotm.net and Burchard et al., 1999). This model simulates the most important hydrodynamic and thermodynamic processes related to vertical mixing in natural waters, including different parameterisations for turbulent processes. The ERSEM-BFM model was used to simulate chemical cycling and lower-trophic-level communities: this model was jointly developed by Cefas and NIOZ from the original ERSEM and BFM codes.
The ERSEM model (Baretta et al., 1995; Ruardij and Raaphorst, 1995; Ruardij et al., 1997; Ebenhöh et al., 1997) was developed in the 1990s to represent marine biogeochemical processes with the specific aim to model functional types (rather than species) and allow for internally varying nutrient ratios within its organisms. It incorporates four phytoplankton types (diatoms, flagellates, picophytoplankton, dinoflagellates), four zooplankton types (microzooplankton, heterotrophic nanoflagellates, omnivorous and carnivorous mesozooplankton), five benthic types (megabenthos, deposit feeders, filter feeders, meiobenthos, infaunal predators), and pelagic and benthic (aerobic and anaerobic) bacteria. The dynamic cycles for nitrogen, phosphorous, silicate, oxygen and carbon are included. The sediment is divided into three layers of varying depth: the oxic layer, denitrification layer, and anoxic layer.

Subsequent reprogramming of ERSEM in Fortran 95 led to the formation of the more modular BFM model (Biological Flux Model; see http://bfm-community.eu) in the early 20th century. This code was applied in oceanic form (Vichi et al., 2003, 2004, 2007), as well as in shelf seas applications (Ruardij et al., 2005). The ERSEM-BFM code applied here stems from further development by Cefas and NIOZ of the shelf seas BFM code: it therefore includes specific processes to represent shelf seas dynamics not found in ERSEM or BFM codes. Additional functional types include small diatoms and Phaeocystis colonies in phytoplankton, pelagic filter feeder larvae in zooplankton, and young filter feeders in benthos. Thus the ERSEM-BFM model includes benthic larvae with a distinct pelagic phase. Further additions include production of transparent exopolymer particles (TEP) by nutrient-stressed diatoms and Phaeocystsis, leading to macro-aggregate formation and increased sinking rates. A simple Suspended Particulate Matter (SPM) parameterisation, assuming proportionality to bed-shear stress induced by surface waves, has been included as described in Van der Molen et al. (2014) to improve representation of the underwater light climate. Improvements in benthic-pelagic coupling have led to a benthic module comprising 53 state variables; see Van der Molen et al. (2013) for more details including validation for benthic-pelagic exchange. For other applications of the ERSEM-BFM model, see van Leeuwen et al. $(2013,2015)$. A closed nitrogen budget was obtained for 1DV setups (one dimension vertical: a water column setup) by reintroducing all lost nitrogen $\left(\mathrm{N}_{2}\right.$ escape to the atmosphere) as atmospheric deposition.

\subsection{Higher trophic levels}

A size-structured model was used to represent the higher trophic levels of the marine food web. This model (see Blanchard et al., 2009, for more details) incorporates the two main marine carbon pathways: via size-based predation (by pelagic or benthic predators) or via unstructured feeding based on a common food source (by detritivores, au- 
Table 1. Distribution of planktonic food supply for pelagic predators.

\begin{tabular}{ll}
\hline Size range $[\mathrm{g}]$ & Food source \\
\hline $10^{-12}-10^{-9}$ & $\begin{array}{l}\text { picophytoplankton, } \\
\text { heterotrophic nanoflagellates }\end{array}$ \\
$10^{-9}-10^{-6}$ & diatoms, flagellates, microzooplankton \\
$10^{-6}-10^{-3}$ & diatoms, flagellates
\end{tabular}

totrophs, and herbivores). The two modelled size spectra (referred to here as fish/predators and detritivores) are linked via size-selective feeding of predators on detritivores. Fisheries yield is calculated as the mortality due to fishing pressure on commercial-sized fish (i.e. predators $>10 \mathrm{~g}$ wet weight $(\mathrm{gWW}))$.

Key processes such as food assimilation, growth, mortality and fishing pressure are included, with ambient temperature effects on feeding rates (and thus growth) incorporated. The size-structured approach is a strong simplification of the complex marine food web but has been shown effective in simulating marine biomass and abundance across the marine system (Blanchard et al., 2009, 2010). Without species representation the model is flexible enough to apply to different sites for long-term simulations, and it allows for a qualitative description of the studied effects.

\subsection{Coupling}

Coupling of the lower and higher-trophic-level models was achieved one way upwards, with GOTM-ERSEM-BFM simulated, time-varying, plankton biomass (for diatoms, flagellates, picophytoplankton, microzooplankton, and heterotrophic nanoflagellates) inserted into their respective size class of the higher-trophic-level predator size spectrum (see Table 1). Benthic detritus from ERSEM-BFM was used as a time-varying food source for detritivores, while simulated sea surface and near-bed temperatures were used to control feeding rates for predators and detritivores respectively. There was no influence of higher-trophic-level biomass on lower-trophic-level dynamics. Fish predation mortality in ERSEM-BFM is simulated as cannibalism of the largest species, ensuring a dynamic mortality dependent on biomass. Thus both lower-trophic-level mortality and higher-trophiclevel feeding were driven by lower-trophic-level biomass values, ensuring a proportionate response. Note that dinoflagellates and Phaeocystis were not used as food as these are predominantly inedible. Mesozooplankton was not included as food as it overlaps with the start of the pelagic predator size spectrum. The applied coupling allows bottom-up pressures like indirect impacts on the abiotic environment to travel up the marine food web, with consequences for commercial fisheries yield, for example.

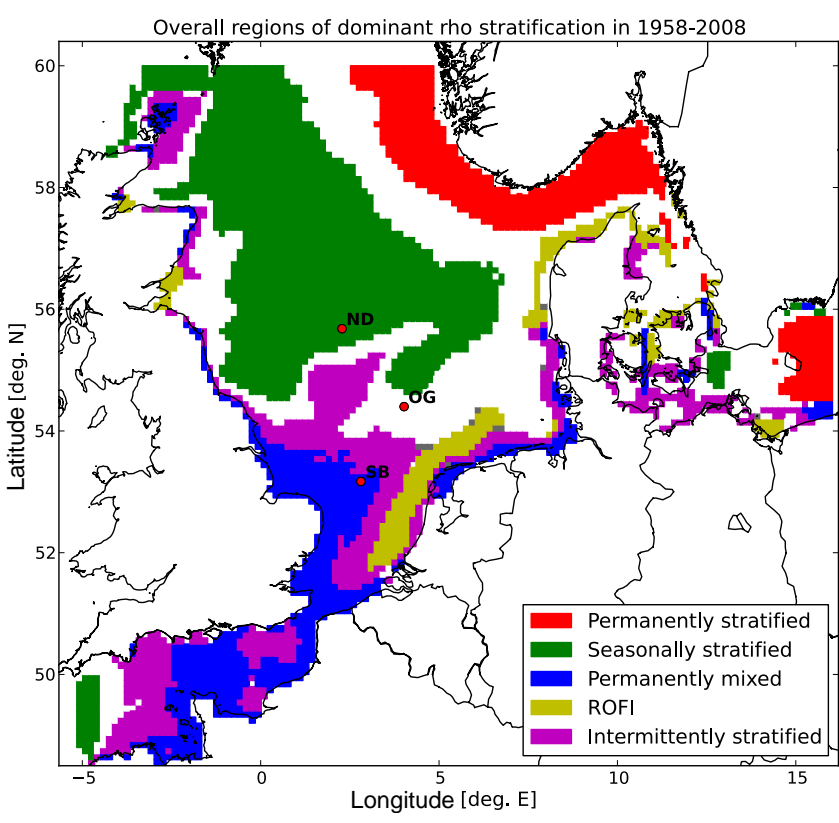

Figure 1. Location of the three sites in the North Sea, imposed on a map of dominant vertical density stratification regimes. ROFI stands for "regions of freshwater influence". The white areas represent transitional waters, which experience large variability in duration of mixed and stratified conditions, defying classification. From van Leeuwen et al. (2015).

\subsection{Locations}

Three locations have been chosen in the North Sea, a shallow shelf sea located on the European shelf (Fig. 1, Table 2). The North Dogger (ND) site is located at $55.68^{\circ} \mathrm{N}$, $2.28^{\circ} \mathrm{E}$. This site is characterised by seasonal, thermal stratification; a depth of $85 \mathrm{~m}$; and a muddy, sandy bed type. The Oyster Grounds (OG) site, at $54.4^{\circ} \mathrm{N}, 4.02^{\circ} \mathrm{E}$, represents transitional waters with frequent seasonal thermal stratification of varying duration (i.e. large inter-annual variability), a medium depth of $45 \mathrm{~m}$ and typically a muddy-sandy substrate. The Southern Bight site (SB, also known as Sean Gas Field) is located at $53.17^{\circ} \mathrm{N}, 2.81^{\circ} \mathrm{E}$ in the well-mixed area of the southern North Sea, and has a depth of $31 \mathrm{~m}$ and a mobile sandy bed. Together, the three sites represent two of the major stratification regimes in the North Sea area and transitional waters (which can vary between regimes), as shown in Fig. 1. For more details on the different regimes see van Leeuwen et al. (2015).

\subsection{Model validation}

Extensive validation of the GOTM-ERSEM-BFM model for the three sites has been published in Van der Molen et al. (2013). In general most variables were within the correct order of magnitude compared to observations. The model underestimated benthic detritus at the ND and OG sites (due to underestimation of pelagic detritus supply and bioturbation) 
Table 2. Overview of locations used. See also Fig. 1.

\begin{tabular}{lllll}
\hline Site & Location & Depth & Hydrodynamic regime & Substrate \\
\hline North Dogger (ND) & $55.68^{\circ} \mathrm{N}, 2.28^{\circ} \mathrm{E}$ & $85 \mathrm{~m}$ & seasonally stratified & muddy sands \\
Oyster Grounds (OG) & $54.4^{\circ} \mathrm{N}, 4.02^{\circ} \mathrm{E}$ & $45 \mathrm{~m}$ & transitional waters & muddy sands \\
Southern Bight (SB) & $53.17^{\circ} \mathrm{N}, 2.81^{\circ} \mathrm{E}$ & $31 \mathrm{~m}$ & permanently mixed & mobile sands \\
\hline
\end{tabular}

and general validation for bed and near-bed processes was poor for the SB site (due to lack of pore water exchange). Additional spatial validation results (showing representation of vertical distribution of phytoplankton) are available in van Leeuwen et al. (2013).

The lack of observations aggregated on the size-spectra scale hinders validation of the size-structured model representing the upper layers of the marine food web. Observations presented in Jennings et al. (2002) and Maxwell and Jennings (2006) (for predators and detritivores respectively) have shown good validation results in Blanchard et al. (2009) for the size-structured model alone. Here, data from Maxwell and Jennings (2006) were used for calibration of the ERSEM-BFM near-bed detritus levels (indicated to be underestimated by Van der Molen et al., 2013) as supplied to the size-spectrum model, while the data from Jennings et al. (2002) were used for validation. Calibration factors (used to multiply the benthic detritus supply to the size-based model) were $25,2.5$, and 5 for the ND, OG, and SB sites respectively. Griffith et al. (2012) showed the importance of including fishing pressure combined with acidification and temperature pressures in an Australian ecosystem. Here fishing pressure was included in the model as a nominal pressure (based on ICES, 2005), but was not calibrated to represent site-specific mortalities.

A reference run with ECMWF (European Centre for Medium-range Weather Forecasts) meteorological forcing covering 1958-2008 was used for validation (ERA-40 and ERA-15 data, UK Met Office). The selected validation period was 1979-2008 to allow for model spin-up of the benthic system. Figure 2 shows the validation results for the resulting higher trophic levels in a normalised Taylor diagram (Jolliff et al., 2009). This diagram shows the correlation coefficient (information regarding phase agreement, shown on the radial axis) and the normalised standard deviation (information regarding amplitude comparison, shown on polar axis) between modelled and observed data.

Validation results for the three sites are very similar, with high correlation factors, reflecting the general size-based structure of the marine ecosystem (Kerr, 1974; Sheldon et al., 1977; Kerr, 2001) and the small geographic area. More observations on a size-spectrum scale are necessary to allow for any quantitative application of the size-based model. Note that the large difference in variability between predators and detritivores can indicate both either a limitation of the model system (lacking stabilising processes for detritivores or ben-

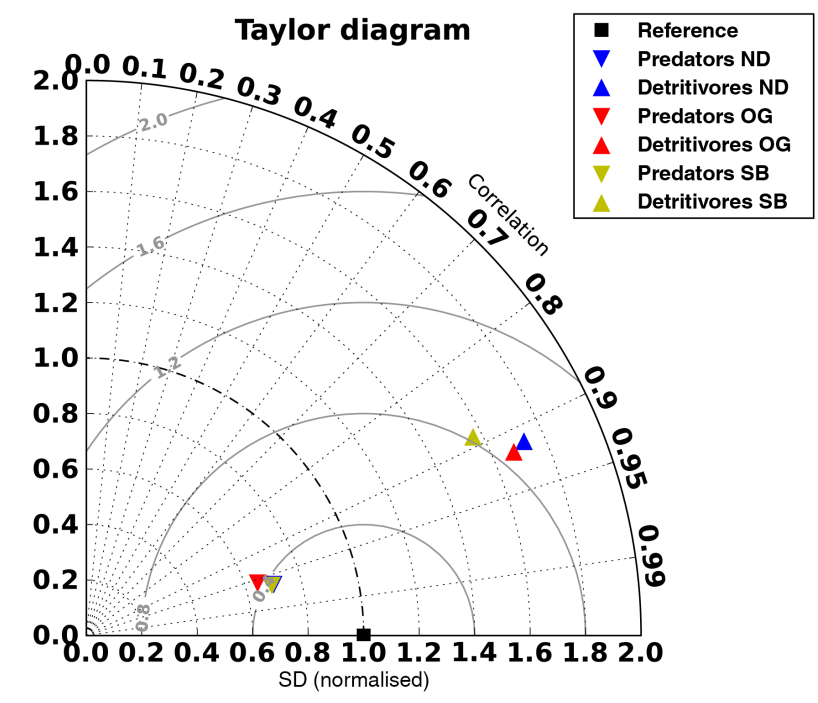

Figure 2. Taylor diagram for predator and detritivore abundance from the coupled model (51-year average) with respect to timeaveraged observations. Note that observations for detritivores were used for calibration purposes, so that predator observations provide the only validation of the higher trophic levels here. Predator abundance results for the North Dogger site overlap with those of the Southern Bight site. The internal grey arcs represent the root-meansquare error.

thic POC supply) and a limitation of the observational data applied (covering only one spring and one autumn cruise, therefore lacking a full seasonal signal and inter-annual variability between seasons).

\subsection{Scenario setup}

The objective of this paper is to provide a first qualitative estimate of effects of ocean acidification on the marine food web across trophic levels relative to climate change effects. To this end, we use a water column model in three separate sites which together are representative of a large part of the North Sea (see Fig. 1). Hydro-biogeochemical conditions at these sites were simulated for the period 1958-2008, using ECMWF forcing data (UK Met Office), for validation purposes (reference simulation). Future and past conditions were simulated for the period 1958-2089 (climate change simulation), using meteorological forcing from the Met Office Hadley Centre Regional Model Perturbed Physics Ensemble simulations (HadRM3-PPE-UK; see Met Office, 
Table 3. Simulated scenarios. p_sN4N3 is the pelagic-specific nitrification rate (in 1/d) in ERSEM-BFM, while $K_{v}$ represents the net growth conversion efficiency (-) for detritivores in the size-structured model. LTL refers to the lower-trophic-level model (ERSEM-BFM) and HTL to the higher-trophic-level model (size-based code).

\begin{tabular}{l|cc|cc|cc|cc}
\hline Scenario & Reference & \multicolumn{2}{c|}{ Low } & \multicolumn{2}{c|}{ Medium } & \multicolumn{2}{c}{ High } \\
\hline Parameter & p_sN4N3 & $\mathrm{K}_{v}$ & p_sN4N3 & $\mathrm{K}_{v}$ & p_sN4N3 & $\mathrm{K}_{v}$ & p_sN4N3 & $\mathrm{K}_{v}$ \\
\hline Reduction & & & $10 \%$ & $2 \%$ & $30 \%$ & $6 \%$ & $50 \%$ & $10 \%$ \\
\hline Reference & 0.16 & 0.2 & & & & & & \\
LTL & & & 0.144 & 0.2 & 0.112 & 0.2 & 0.08 & 0.2 \\
HTL & & & 0.16 & 0.196 & 0.16 & 0.188 & 0.16 & 0.18 \\
LTL+HTL & & & 0.144 & 0.196 & 0.112 & 0.188 & 0.08 & 0.18 \\
\hline
\end{tabular}

2008; Murphy et al., 2007), as supplied by BADC (British Atmospheric Data Centre). These simulations focus on regional UK climate (1950-2100) and represent a historical and medium emissions scenario (SRESA1B). Only the unperturbed member of the ensemble was applied here as forcing, and data from the nearest HadRM3 grid cell ( $25 \mathrm{~km}$ resolution) for each site was used. For a detailed overview of climatological changes during the simulated period, see Van der Molen et al. (2013), especially their Fig. 5. In general, the applied forcing is characterised by increasing air temperatures and decreasing cloud cover at all three sites. Pressure increases at all sites but with considerable inter-annual variability. Wind speeds show an increase in the period up to 2030, followed by a strong decrease at all sites. Relative humidity exhibits an increase at the ND and OG sites, but a decline at the SB site.

Three main impacts on the marine environment were studied:

1. climate change, acting on the abiotic environment, lower trophic levels, and higher trophic levels;

2. decreased pelagic nitrification (indirect effect of ocean acidification; see Huesemann et al., 2002; Hutchins et al., 2009; Beman et al., 2011), acting on the lower trophic levels;

3. reduced detritivore growth rate (direct effect, i.e. reduced growth of calcifying organisms; Doney et al., 2009; Andersson and Mackenzie, 2012; Wicks and Roberts, 2012, and references therein), acting on higher trophic levels.

Low, medium, and high reduction rates were applied to allow for uncertainties in future emission predictions and acidification impact on different species. Table 3 lists the different scenarios and the parameter values used in each. For pelagic nitrification, reductions of 10,30 , and $50 \%$ were applied, while for reduced detritivore growth rate, reductions of 2, 6 , and $10 \%$ were imposed. The latter values reflect not just observed reductions in calcifying capacity but also the percentage of simulated detritivores representing calcifying organisms. Note that community structure observations would be necessary to interpret localised effects of reduced detritivore growth rate. Climatic effects thus affect both fish and detritivore growth rates, while reduced growth efficiency is applied solely to detritivores.

Simulations covered the period 1958-2098, of which the first 20 years are considered model spin-up time. To estimate temperature impacts we calculated the relative difference in a variable between the 30-year averaged value for the period 1979-2009 (current state) and 2069-2098 (future state) of the climate change simulation. To estimate acidification effects we considered the relative difference in a variable in the period 2069-2098 (30-year averaged value) between the climate change simulation and the scenario simulation (climate change and ocean acidification). This approach differs from that used by Van der Molen et al. (2013), which compared results to a reference simulation (1958-2098) with repeated current climate conditions. A comparison study showed minor changes between the two approaches.

\section{Impact of decreased pelagic nitrification and climate change}

Published effects of ocean acidification impacts on pelagic nutrient supply include a predicted decline in water column nitrification (Hutchins et al., 2009). The lower-trophiclevel experiments mimic this effect by reducing the pelagic nitrification rate in the ERSEM-BFM model (parameter p_sN4N3). ERSEM-BFM does not explicitly model $\mathrm{NH}_{3}$ or $\mathrm{NO}_{2}^{-}$, so the nitrification rate relates to the transformation of $\mathrm{NH}_{4}^{+}$to $\mathrm{NO}_{3}^{-}$. Note that processes related to $\mathrm{NH}_{3}$ $\left(\mathrm{NO}_{2}^{-}\right)$will be included via direct effects on the internal $\mathrm{NH}_{4}^{+}$ $\left(\mathrm{NO}_{3}^{-}\right)$pools. Urea is explicitly modelled in ERSEM-BFM, and forms an integral part of the model's nitrogen cycle.

Simulation results for biomass showed site-specific responses; see Table 4 and Figs. S1, S2, and S3 in the Supplement. 
Table 4. Simulated results for lower-trophic-level impacts: percentage change for all sites and scenarios [\%] (2069-2098 vs. 1979-2009; T represents the climate change scenario) and actual values $\left(\mathrm{g} \mathrm{C} \mathrm{m}^{-2} \mathrm{~d}^{-1}\right.$ for lower-trophic-level results and $\mathrm{g}$ wet weight $\mathrm{m}^{-2}$ for fisheries results) of depth-integrated, 30-year averages. The actual values refer to the period 1979-2009 of the climate change scenario simulation. POC refers to particulate organic carbon.

\begin{tabular}{|c|c|c|c|c|c|c|c|c|c|c|c|c|c|c|c|c|}
\hline \multirow[t]{2}{*}{ Variable } & & \multicolumn{5}{|c|}{ ND } & \multicolumn{5}{|c|}{ OG } & \multicolumn{5}{|c|}{ SB } \\
\hline & & Low & Med. & High & $T$ & Actual & Low & Med. & High & $T$ & Actual & Low & Med. & High & $T$ & Actual \\
\hline LTL & phytoplankton & 0 & 1 & 2 & -6 & 1.3 & -0 & -0 & -1 & -2 & 1.5 & -0 & -1 & -1 & 11 & 1.5 \\
\hline \multirow{4}{*}{ Biomass } & zooplankton & 1 & 2 & 3 & -2 & 0.5 & -0 & 0 & 0 & -2 & 0.5 & -0 & -0 & -1 & 6 & 0.3 \\
\hline & pelagic bacteria & 0 & 0 & 1 & -1 & 0.5 & -0 & -1 & -1 & -3 & 0.3 & -0 & -1 & -1 & 13 & 0.3 \\
\hline & benthos & 0 & -2 & -5 & -20 & 1.6 & -0 & 0 & -0 & -17 & 3.5 & -1 & -4 & -8 & -19 & 1.6 \\
\hline & benthic bact. & 1 & 2 & 4 & -13 & 0.05 & -0 & -0 & -0 & -7 & 0.15 & -0 & -2 & -4 & -14 & 0.07 \\
\hline \multirow{2}{*}{$\begin{array}{l}\text { Primary } \\
\text { production }\end{array}$} & net & 1 & 2 & 3 & 11 & 0.3 & 0 & -1 & -1 & 10 & 0.4 & -1 & -2 & -2 & 50 & 0.5 \\
\hline & chlorophyll $a$ & 1 & 0 & 3 & -2 & 0.03 & -0 & -1 & -1 & 2 & 0.03 & -0 & -1 & -1 & 20 & 0.03 \\
\hline \multirow[t]{2}{*}{ POC } & pelagic & 2 & 3 & 3 & -10 & 16.2 & 0 & -1 & -1 & -15 & 7.5 & -0 & -0 & -1 & 0 & 15.8 \\
\hline & benthic & 2 & 3 & 8 & -4 & 4.1 & -0 & -0 & -1 & 5 & 25.8 & -1 & -3 & -7 & 0 & 11.3 \\
\hline HTL & fish & 24 & 24 & 30 & 20 & 3.1 & -6 & -8 & -9 & -6 & 2.7 & 25 & 21 & 17 & 27 & 1.8 \\
\hline \multirow[t]{2}{*}{ biomass } & detritivores & 13 & 13 & 30 & 6 & 2.4 & 10 & 12 & 14 & 10 & 4.2 & -33 & -38 & -46 & -32 & 2.6 \\
\hline & fish yield & 33 & 33 & 42 & 27 & 2.0 & 0 & -1 & -1 & 1 & 1.9 & 16 & 11 & 5 & 18 & 1.2 \\
\hline
\end{tabular}

North Dogger

(a)

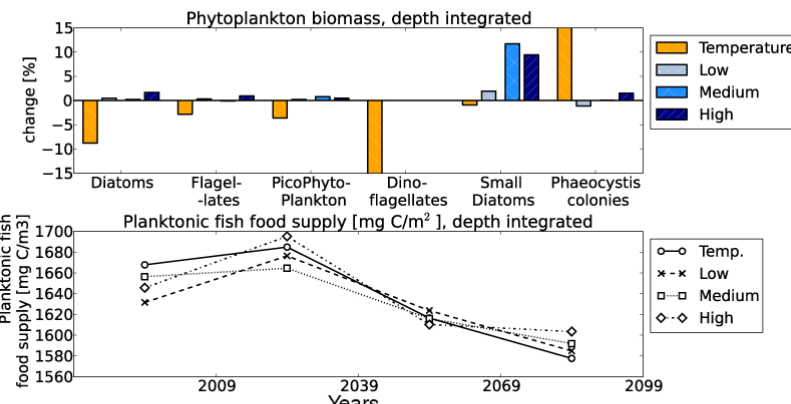

(e)

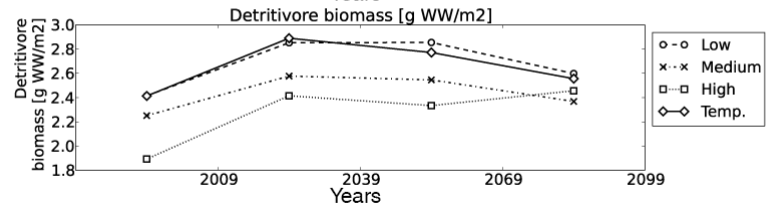

(g)

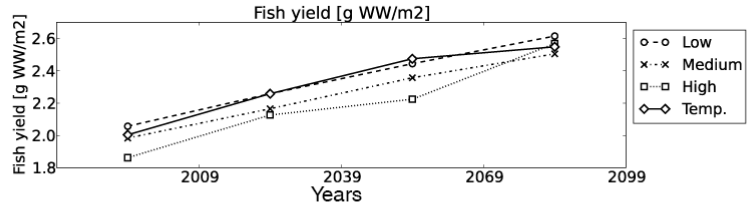

(i)

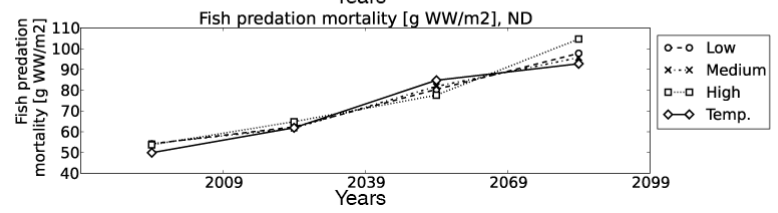

(b)

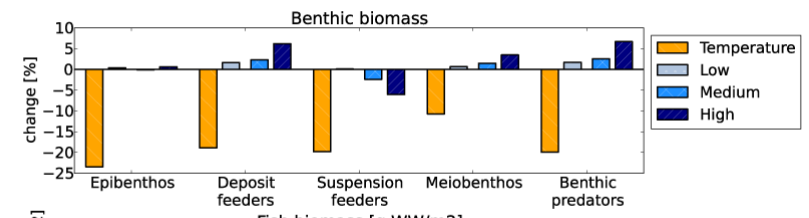

(d)

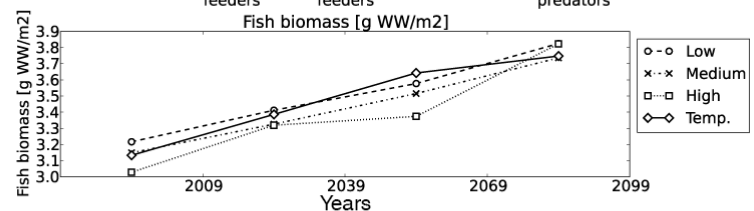

(f)

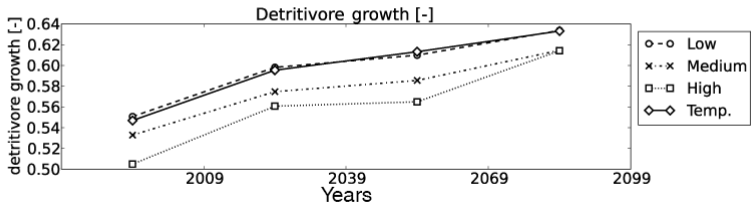

(h)

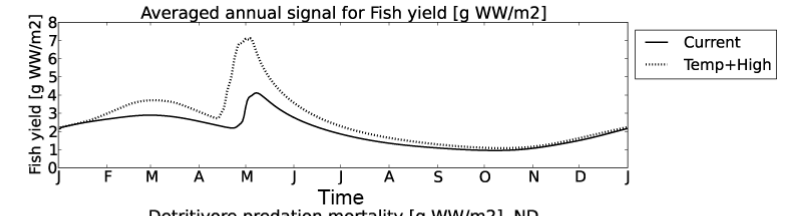

(j)

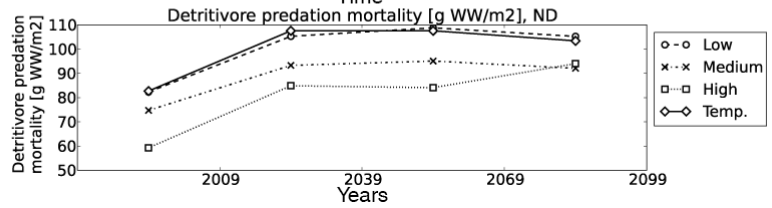

Figure 3. North Dogger: 30-year averaged values, climatic plus high ocean acidification (LTL + HTL) effects - (a) phytoplankton changes [\%]; (b) benthos changes [\%]. Both (a) and (b) display the 2069-2098 change compared to 1979-2009. (c) planktonic fish food; (d) fish or pelagic predator biomass; (e) detritivore biomass; (f) detritivore growth rates; (g) fish yield; (h) annual fish yield, signal for the current time (1979-2008 climate scenario) and the high-impact scenario (2069-2098 climatic plus LTL + HTL acidification effects) signal; (i) predated biomass for pelagic predators; and (j) predated biomass for detritivores. Maximum values outside of axis range for phytoplankton changes are $-100 \%$ for dinoflagellates (small levels were wiped out) and $+241 \%$ for Phaeocystis (small original biomass). 


\section{Oyster Grounds}

(a)

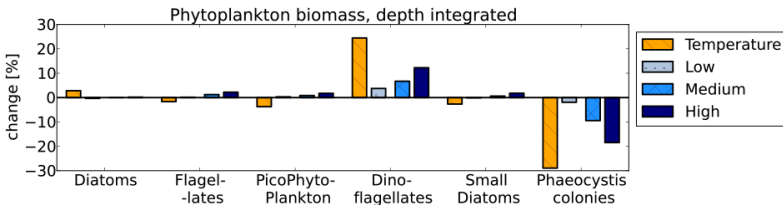

(c)

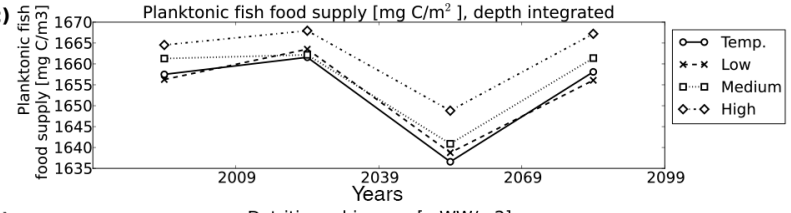

(e)

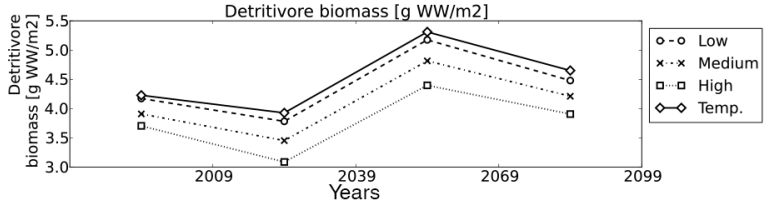

(g)

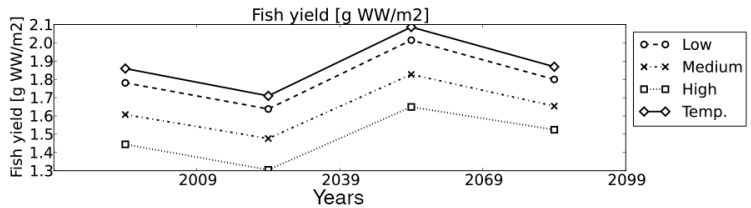

(i)

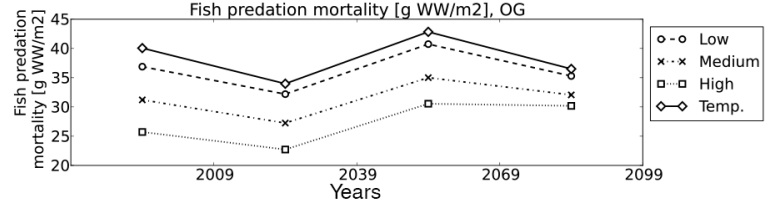

(b)

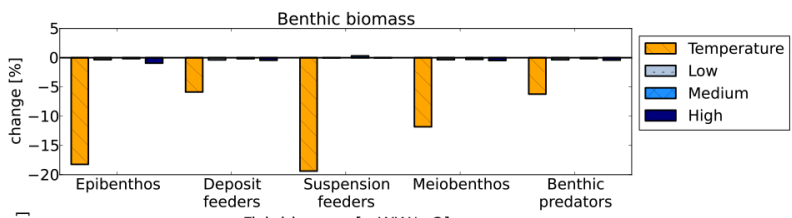

(d)

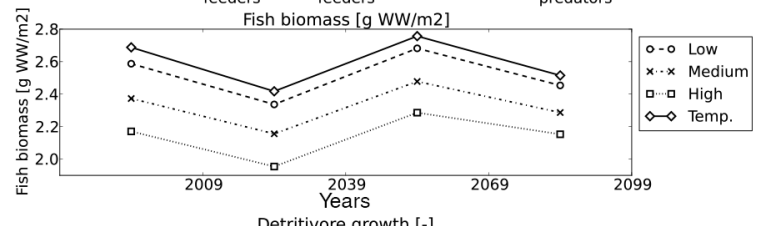

(f)

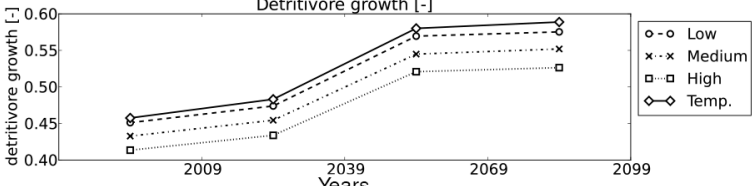

(h)

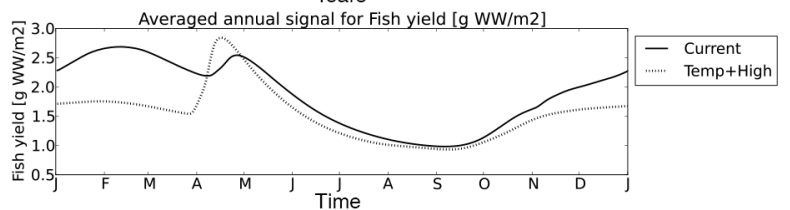

(j)

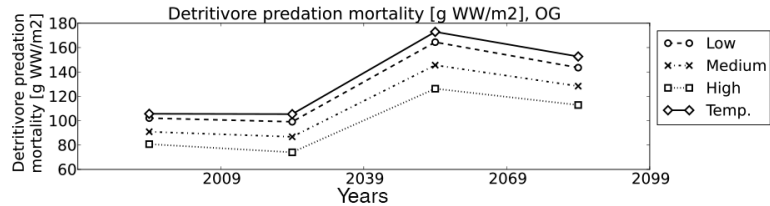

Figure 4. Oyster Grounds: 30-year averaged values, climatic plus high ocean acidification (LTL + HTL) effects - (a) phytoplankton changes [\%]; (b) benthos changes [\%], both 2069-2098 change compared to 1979-2009; (c) planktonic fish food; (d) fish or pelagic predator biomass; (e) detritivore biomass; (f) detritivore growth rates; (g) fish yield; (h) annual fish yield, signal for the current time (1979-2008 climate scenario) and the high-impact scenario (2069-2098 climatic plus LTL + HTL acidification effects) signal; (i) predated biomass for pelagic predators; and (j) predated biomass for detritivores.

\subsection{North Dogger}

The seasonally stratified site was characterised by a negative impact of future climate conditions on lower-trophiclevel pelagic and benthic biomass levels (see also Fig. 3a, b). Net primary production increased due to increased metabolic processes (resulting in higher pelagic turn-over rates) and a lengthening of the growing season due to an earlier start of the spring bloom (Van der Molen et al., 2013). A strong increase in Phaeocystis was observed (Fig. 3a), but this was relative to originally very low biomass values $\left(6 \mathrm{mg} \mathrm{C} \mathrm{m}^{-2} \mathrm{~d}^{-1}\right)$. Benthic biomass declined due to a decline in the (main) diatom food source, as a result of increased zooplankton grazing on diatoms. The rise in ambient water temperatures caused higher-trophic-level growth rates to increase (favouring fish as stratification limited near-bed temperature increases), resulting in higher biomass for both fish and detritivores despite the minor decrease in planktonic food supply. Fish yield increased accordingly.

Ocean acidification effects on the abiotic environment (Fig. S1) showed only a minor impact on lower-trophic-level dynamics at this site. Percentage change for picophytoplankton (Figs. 3a and S1a) was small due to high original biomass levels (highest of all the three sites) but increases were observed both in spring and summer accompanied by reduced grazing. Benthic biomass decline was due to decreased levels of filter feeders (the dominant functional group): all other benthic functional groups increased their biomass levels (see Figs. $3 \mathrm{~b}$ and S1b). Benthic bacteria biomass levels increased slightly as the benthic system became more bacterial orientated. Increased plankton biomass led to increased levels of particulate organic carbon (POC), causing increased levels of both fish and detritivore biomass due to increased food supply (Fig. S1c, d, i, and j). As a result, fisheries yield increased (note that increased food supply and higher ambient temperatures caused a non-linear increase in higher-trophiclevel biomass, resulting in large percentage differences for the separated acidification effects).

Overall, climatic changes and acidification impact on the abiotic environment both had a positive impact on future fisheries yield at this site, and were of a similar order of magnitude. 


\subsection{Oyster Grounds}

Climate change impacts only reduced pelagic biomass slightly at this site, with a larger impact on benthic functional groups (Fig. 4b), indicating again a shift towards a more pelagic-orientated system. Net primary production increased at this site, due to faster recycling of nutrients and a longer growing season (characterised by an earlier spring bloom due to reduced wind speeds; see Van der Molen et al., 2013: Fig. 9).

Onset of stratification (a trigger for diatom sinking) did not change significantly at this site, leading to a longer period of suspended diatoms and a reduction in near-bed diatom levels during spring (longer grazing period for zooplankton). This led to a decline in filter feeder biomass (due to a reduction in the main food supply) and a subsequent reduction in other benthic functional groups as pelagic-feeding filter feeders form the main carbon pathway into the benthic system in the model (Van der Molen et al., 2013). As a result, benthic POC levels increased.

The overall reduction in phytoplankton and zooplankton biomass did not significantly change the planktonic food supply for fish (Figs. 4a and S2c, diatom increase compensated for loss of other functional groups). Predation on detritivores increased (Fig. S2j, reflecting increased detritivore biomass) but fish predation declined (Fig. S2i, reflecting decreased fish biomass), showing a change in feeding behaviour for pelagic predators. Fisheries yield showed a negligible, positive change (Fig. S2g, h), indicating that fish biomass decrease was limited mainly to non-commercial size fish. The decline in fish biomass may therefore be due to increased predator growth rates causing increased predation pressure on smaller size fish.

Impacts of reduced nitrification (acidification impact) at this site were minor, as climate change effects countered acidification impacts with increasing sea temperatures. Decreased nitrification favoured organisms with a high ammonium affinity, like picophytoplankton (spring bloom increase) and dinoflagellates (autumn bloom increase at the expense of Phaeocystis). Fish biomass was negatively impacted, while detritivores were marginally positively impacted (Fig. S2d, e). Fisheries impacts were negligible.

In all, climatic effects dominated at this site over abiotic environmental effects of ocean acidification for lower trophic levels but were of the same order of magnitude for higher trophic levels (except for detritivore levels, where the main driver was climate). Acidification effects showed a reduced signal strength with increasing climate impact on higher trophic levels, indicating a non-additive effect of the combined stressors. Impact on fisheries yield was positive (climate change) but became negligible in combination with the high-acidification scenario.

\subsection{Southern Bight}

The well-mixed site in the southern bight showed a large increase in net primary production under future climate conditions (no OA effects included). Higher sea temperatures led to faster recycling of nutrients, and an associated increase in regenerated production. With a closed nutrient budget the main driver for the large productivity increase was likely the improved light conditions, as suggested by decreased cloud cover at this site and episodic reductions in SPM concentrations in summer (Van der Molen et al., 2013). Contrary to the other two sites, the growing season did not lengthen here (Van der Molen et al., 2013). The large decline in diatoms resulted in a loss of benthos biomass (Fig. 5b) and a shift towards a more pelagic-orientated system. Increased planktonic biomass led to a decrease in planktonic food supply for fish (Fig. S3c) as the increases were limited to inedible functional groups (dinoflagellates and Phaeocystis colonies). Therefore increased growth rates for fish are deemed responsible for the large increase in fish biomass and associated fisheries yield (Fig. S3d, g). Predation mortality biomass for detritivores remained constant (Fig. S3j), indicating increased predation on lower biomass levels.

Reduction of pelagic nitrification rates (acidification impact) resulted in higher pelagic ammonium concentrations and lower nitrate levels, favouring phytoplankton species with high ammonium preference like picophytoplankton (also experiencing decreased predation) and dinoflagellates (Figs. 5a and S3a). Accompanying loss of diatom and Phaeocystis biomass led to virtually no effect on overall plankton biomass and net primary production levels. Benthic biomass decreased due to decreased diatom levels (a main food source for suspension feeders) and decreased pelagic detritus generation, resulting in less benthic detritus (both labile and particulate) and associated loss of benthic bacteria (also a food source for benthos). Planktonic food supply for fish decreased more with increased climate pressure, again displaying a non-additive response. Fish and detritivore levels were negatively impacted by indirect acidification impacts (Fig. S3d, e).

Here, climate effects dominated over acidification effects on the abiotic environment for lower trophic levels, showing a strong shift towards a more pelagic-oriented system. Impacts on higher-trophic-level biomass were of the same order of magnitude but of opposing trend for fish (same negative trend for detritivores). Fish biomass increased and detritivore biomass decreased, but fisheries yield (trend) depended strongly on acidification impact strength.

\section{Impact of reduced detritivore growth rate and climate change}

Reduced growth of calcifying organisms was represented by reductions in the size-based model of the net growth con- 
Southern Bight (Sean Gas Field)

(a)

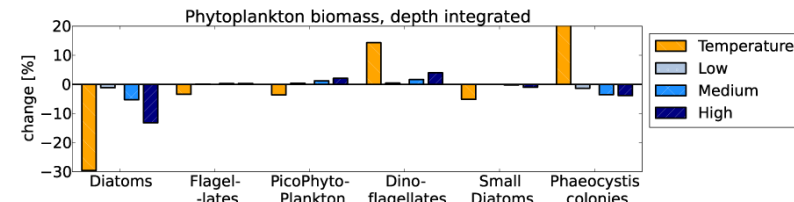

(c)

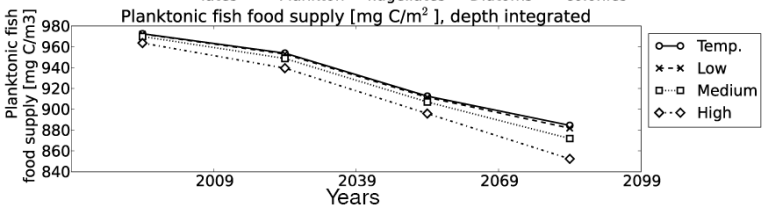

(e)

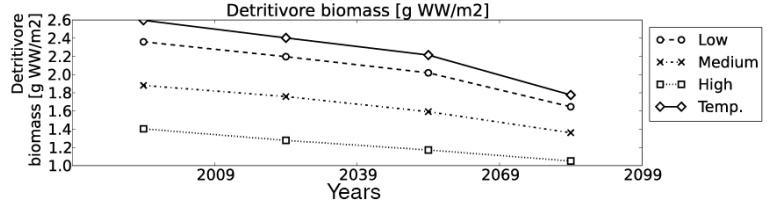

(g)

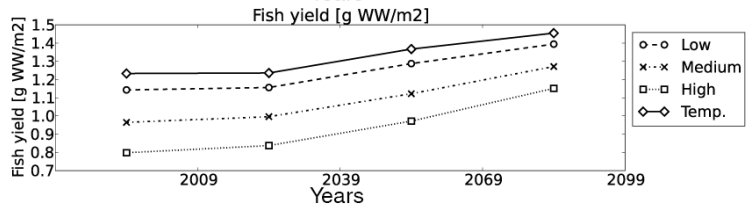

(i)

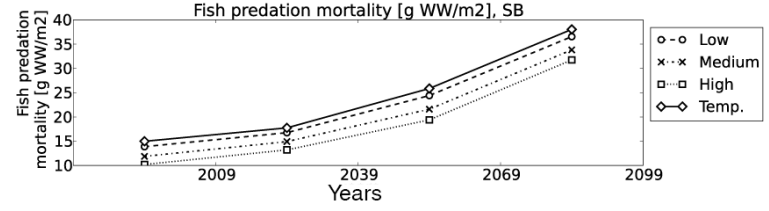

(b)

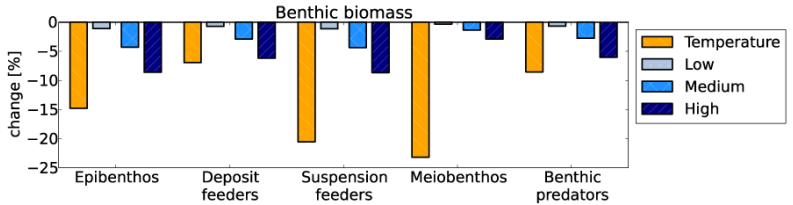

(d)

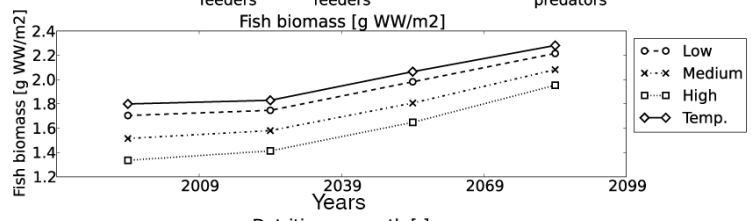

(f)

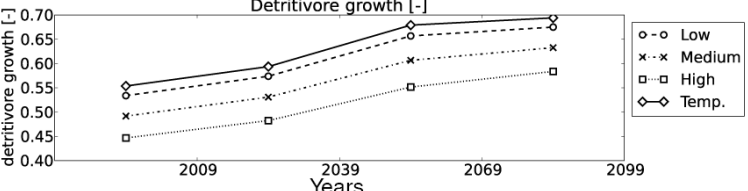

(h)

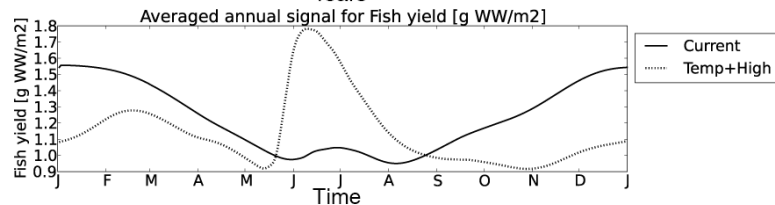

(j)

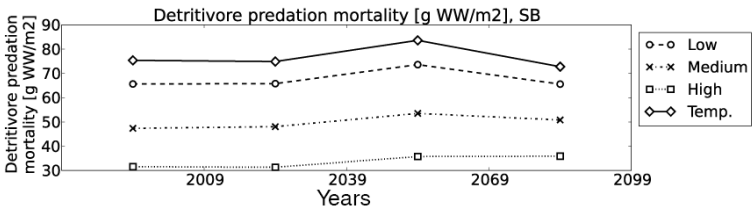

Figure 5. Southern Bight: 30-year averaged values, climatic plus high ocean acidification (LTL + HTL) effects - (a) phytoplankton changes [\%]; (b) benthos changes [\%], both 2069-2098 change compared to 1979-2009; (c) planktonic fish food; (d) fish or pelagic predator biomass; (e) detritivore biomass; (f) detritivore growth rates; (g) fish yield; (h) annual fish yield, signal for the current time (1979-2008 climate scenario) and the high-impact scenario (2069-2098 climatic plus LTL + HTL acidification effects) signal; (i) predated biomass for pelagic predators; and (j) predated biomass for detritivores. Maximum values outside of axis range for phytoplankton changes are $108 \%$ for Phaeocystis.

Table 5. Simulated results for higher-trophic-level impacts only: percentage change for all sites and scenarios [\%] (2069-2098 vs. 19792009; $T$ represents the climate change scenario) and actual values ( $\mathrm{g}$ wet weight $\mathrm{m}^{-2}$ ) of depth-integrated, 30-year averages. The actual values refer to the period 1979-2009 of the climate change scenario simulation.

\begin{tabular}{|c|c|c|c|c|c|c|c|c|c|c|c|c|c|c|c|c|}
\hline \multirow[t]{2}{*}{ Variable } & & \multicolumn{5}{|c|}{ ND } & \multicolumn{5}{|c|}{ OG } & \multicolumn{5}{|c|}{ SB } \\
\hline & & Low & Med. & High & $T$ & Actual & Low & Med. & High & $T$ & Actual & Low & Med. & High & $T$ & Actual \\
\hline \multirow[t]{3}{*}{ HTL biomass } & predator biomass & 18 & 15 & 12 & 20 & 3.1 & -9 & -13 & -18 & -6 & 2.7 & 25 & 21 & 17 & 27 & 1.8 \\
\hline & detritivore biomass & 1 & -8 & -17 & 6 & 2.4 & 6 & -2 & -11 & 10 & 4.2 & -35 & -42 & -48 & -32 & 2.6 \\
\hline & fish yield & 25 & 20 & 15 & 27 & 2.0 & -3 & -10 & -17 & 1 & 1.9 & 15 & 9 & 4 & 18 & 1.2 \\
\hline
\end{tabular}

version efficiency for organisms in the detritivore size spectrum (parameter $K_{v}$ ). Modelled growth rates therefore depend on ambient temperature, growth conversion efficiencies, and food availability; see Blanchard et al. (2009). Results are presented in Table 5 and Figs. S4, S5, and S6.

\subsection{North Dogger}

The deeper, seasonally stratified site showed that impact of ocean acidification effects on species level could be of the same order of magnitude as climatic impacts (Fig. S4), with dominant impact on parts of the ecosystem (here detritivore levels). The negative impact of reduced detritivore growth rates was initially offset by increased food supply (POC) but showed a strong negative effect for the medium- and highimpact scenarios, resulting in lower detritivore biomass than current conditions. This reduction in part of the food supply for fish led to lower fish biomass with strengthening of the acidification impact (general increase due to increased planktonic food supply and increased growth rates). 
Table 6. Simulated results for combined lower- and higher-trophic-level impacts: percentage change for all sites and scenarios [\%] (20692098 vs. 1979-2009; $T$ represents the climate change scenario) and actual values ( $\mathrm{g}$ wet weight $\mathrm{m}^{-2}$ ) of depth-integrated, 30-year averages. The actual values refer to the period 1979-2009 of the climate change scenario simulation.

\begin{tabular}{|c|c|c|c|c|c|c|c|c|c|c|c|c|c|c|c|c|}
\hline \multirow[t]{2}{*}{ Variable } & & \multicolumn{5}{|c|}{ ND } & \multicolumn{5}{|c|}{ OG } & \multicolumn{5}{|c|}{ SB } \\
\hline & & Low & Med. & High & $T$ & Actual & Low & Med. & High & $T$ & Actual & Low & Med. & High & $T$ & Actual \\
\hline \multirow[t]{3}{*}{ HTL biomass } & predator biomass & 22 & 19 & 22 & 20 & 3.1 & -9 & -15 & -20 & -6 & 2.7 & 23 & 16 & 9 & 27 & 1.8 \\
\hline & detritivore biomass & 8 & -2 & 2 & 6 & 2.4 & 6 & -0 & -8 & 10 & 4.2 & -37 & -47 & -60 & -32 & 2.6 \\
\hline & fish yield & 31 & 25 & 28 & 27 & 2.0 & -3 & -11 & -18 & 1 & 1.9 & 13 & 3 & -7 & 18 & 1.23 \\
\hline
\end{tabular}

Combined effects indicated increased biomass for fish (climatic impact modified by species-level acidification impact) and decreased levels of detritivore biomass (species-level acidification impact), resulting in increased fisheries yield during the spring bloom under future conditions (Fig. S4h).

\subsection{Oyster Grounds}

At the mid-depth, seasonally stratified site the benthic system forms an integral part of the local ecosystem (Van der Molen et al., 2013). As such, a reduction in detritivore growth efficiency led to a stronger effect on fish biomass than at the other two sites, as fish were more dependent on the detritivore food source (see Fig. S5d, e, i, and j). The larger impact on fisheries shows that the pelagic impact mainly affected commercial size species.

With only a limited climatic impact at this site the specieslevel acidification impact dominated fish dynamics, resulting in biomass loss and reduced fisheries yield. Both impacts were of similar order for detritivores, with climate impacts resulting in increased growth rates (Fig. S5f) despite the reduction applied for calcifying organisms.

\subsection{Southern Bight}

Reduced growth efficiency for detritivores also led to decreased detritivore biomass at the well-mixed site (see also Fig. S6), with fish biomass increases (buoyed by climateinduced increased growth rates) modified due to a reduced detritivore food source (Fig. S6e, i, and j): predated detritivore biomass nearly equalled predated fish biomass under combined stressors.

Climatic impacts dominated over species-level ocean acidification impacts at this site for fish but were of the same order for detritivores, with temperature-induced decline in detritivore biomass significantly enhanced by the direct acidification impact. Fisheries yield was predicted to increase due to climatic impacts (summer increase, winter decrease).

\section{Combined effects: sensitivity of future fisheries yield}

Results for combined impacts from climate and direct and indirect ocean acidification are listed in Table 6 and visualised in Figs. 3, 4, and 5.

\subsection{North Dogger}

Climatic effects and acidification impacts (both abiotic and biotic) were of the same order of magnitude at the seasonally stratified site, with positive results for future fish yields. Indirect ocean acidification impacts compensated for losses due to reduced growth efficiency of detritivores, leading to increases in fish and detritivore biomass driven by climate change (Figs. 3d, e, S1d, e, and S4d, e). Planktonic fish food supply declined due to climatic impacts, but the decline was moderated by positive impacts from acidification effects on the abiotic environment (Fig. 3c). The pelagic food source for predators increased accordingly (climate impact, including increased growth rates, Fig. 3i), while the detritivore food source increased due to climatic impacts (Fig. 3j). Fish yield increased (Fig. 3g), mainly during the spring bloom and prespring bloom periods (Fig. 3h).

\subsection{Oyster Grounds}

Dynamics at the Oyster Grounds site changed mainly due to direct acidification impacts, as benthic communities form an important part of the local ecosystem. Fish biomass declined over time due to acidification impacts at species level (Fig. 4d), while the trend for detritivore levels was strongly dependent on the strength of the acidification impact on species level (Fig. 4e). Detritivore growth rates increased over time (Fig. 4f), but increases were heavily modified due to direct acidification impacts. The larger direct acidification impact on pelagic predators compared to detritivores (Fig. S5d, e) suggests a strong resilience of the comparatively large benthic system at this site. Planktonic fish food supply increased slightly due to indirect acidification impacts (Fig. 4c, increased values compared to climate change scenario) but could not counteract the decline in pelagic predators due to all stressors (climate change, indirect and direct acidification impact). Fisheries yield decreases accordingly (Fig. 4g, acidification scenarios vs. "Temp." scenario), with the main decline in the winter period (Fig. 4h).

\subsection{Southern Bight}

Climatic and acidification effects were equally important at the well-mixed site. Fish biomass increased due to climatic impacts, but was heavily modified by indirect and direct 
acidification impacts (Figs. 5d, S3d, and S6d). Detritivore biomass declined due to all stressors (Figs. 5e, S3e, and S6e), with a dominant role for acidification effects (abiotic environment and species level). Detritivore growth rates remained more or less equal when combined effects were applied (Fig. 5f, "High" scenario 2069-2098 result compared to "Temp." scenario 1979-2008), while planktonic food supply for fish was reduced mainly due to climatic effects (Fig. 5c). Changes to fisheries yield depended strongly on the strength of acidification impacts, affecting all seasons and showing a strong decline in winter and strong increase in summer (Fig. 5g, h). Feeding behaviour showed a strong increase in the reliance on the pelagic food source for fish as detritivore biomass levels decreased (Fig. 5i, j).

\section{Discussion}

Results presented in the last section show regionally differing responses to future pressures. This high spatial variability was also reported by Artioli et al. (2014) using a fully three-dimensional shelf seas model, and can be seen in Skogen et al. (2014) for the Arctic region and in Blanchard et al. (2012) for 11 regional seas. The use of 3-D models adds advective processes, land-based nutrient sources, and far-field influences but generally lacks specific local parameter settings (here bed porosity and increased vertical resolution). As such, the two approaches are complementary. Advective processes and oceanic changes have the potential to outweigh local response. This applies mainly to ocean acidification impacts, as climatic impacts are predominantly a direct response to local meteorology (unless large-scale circulation patterns are altered). Nevertheless, changes in rainfall patterns can cause significant changes in nutrient inputs in shelf seas. The less computationally expensive water column model also allows for many scenario simulations to be performed within a reasonable time frame, and is therefore very suitable for scenario studies including different pressures at different impact levels.

Here, the use of three separate sites within one shelf sea, each calibrated and validated independently (Van der Molen et al., 2013), allows for these regional differences to be investigated. Results for sites located in stable hydrodynamic regimes (North Dogger, Southern Bight) can be indicative for the system stressor response in the associated regime areas (see Fig. 1). However, results for the Oyster Grounds (located in transitional waters) should be interpreted as relating to areas of thermal stratification of varying duration during summer (1-6 months), with medium depths (40-50 m).

The study only emulated the potential impact of two different mechanisms of ocean acidification impacts on marine organisms and marine ecosystem functioning. The outcomes of the study will be sensitive to the assumption regarding the nature of the direct impact of ocean acidification. However, when looking at whole-system-level effects emulating acid- ification effects is challenging based on current understanding of ocean acidification and ecological processes. Where there is no clear effect on a system-level process, individual species-level effects may just lead to changes in community composition with little impact at a whole-system level. Similarly model limitations should also be considered. ERSEMBFM is one of the most advanced lower-trophic-level models available, incorporating (besides multiple functional groups with internally varying nutrient ratios): nitrifying bacteria, urea, TEP, benthic diatoms, pelagic filter feeder larvae, and an extensive benthic module (including pore water processes, bio-irrigation, and bio-turbation). Nevertheless, it remains a simplification of the marine ecosystem. Temperature controls virtually every biological process, and as such any temperature change can be expected to have a large impact on simulated results. The main conclusions therefore cannot identify whether climate impacts are dominant (if they are, this might be the results of the model's extensive implementation of temperature), but can indicate whether simplified ocean acidification impacts are of comparable order to fully included climatic effects. The results showed that this is the case for both the seasonally stratified site and the permanently mixed site, with the site located in transitional waters exhibiting a dominant impact due to ocean acidification. This aligns with the conclusion from Griffith et al. (2012) that ocean acidification was the main driver in a study considering the separate and combined impacts of fishing, acidification, and ocean warming. With respect to the applied size-structured model, both temperature and acidification impacts have been included in limited form. Other environmental consequences (e.g. low oxygen levels; see Van der Molen et al. (2013) for future predictions at these sites) have not been included directly in the higher-trophic-level model. It assumes a size distribution of biomass, neglecting species characteristics, seasonal reproduction, and life stages. As such, it can provide qualitative information about future trends in marine biomass and fish yield, but cannot predict effects on specific commercial species (cold-water species may be replaced by warmerwater ones; see, for example, Cheung et al., 2010 for related impacts on fish yield) or the associated fisheries-landings value. Only a nominal fishing pressure was applied: changes in fishing pressure have the potential to aggravate or relieve the impacts of future pressures. This also applies to the usage of the medium emissions scenario, which is dependent on future management of carbon emissions. Note that the interaction of ambient temperature and abiotic and/or specieslevel acidification impacts is non-linear: the presented values for acidification impacts alone are indicative of the trend due to acidification effects under future climate conditions, but should not be interpreted as percentage changes likely to occur under current climate conditions and increased $\mathrm{CO}_{2}$ levels. Indeed, the results presented here should be seen as a sensitivity test of marine response to future pressures, rather than a prediction of future yields. 
Finally, the linkage between the lower- and higher-trophiclevel model allowed for impact assessment of bottom-up pressures like climate change and acidification throughout the food web. However, top-down pressures like fishing effort only impacted the higher end of the food chain, with no mechanism included to allow for top-down pressures to impact on lower-trophic-level dynamics. Thus, if fishing pressure is to be included in future studies comparing marine pressures a two-way coupled approach is necessary, with fish biomasses impacting on planktonic-level organisms and associated nutrient cycling. This would also ensure feedback of other predator changes (e.g. increased feeding rates due to increased sea temperature, more pelagic-oriented feeding) on planktonic biomass, which are not included in one-way coupling. A two-way coupling should also address the issue of overlapping size spectra: now the intermediate size range of mesozooplankton and the larger benthic groups are represented by both models. This is not expected to have a large impact on results as all overlapping groups are driven by the same food supply and similar (biomass-related) mortalities. But a two-way coupled system needs to eliminate overlapping processes between food supply and mortality to ensure a dynamically balanced system where biomass levels are equally driven by food availability and predation pressure. The bottom-up stressor of nutrient supply should also be considered in future studies, as changes in nutrient availability can change lower-trophic-level dynamics considerably. However, for the North Sea, future changes in nutrient supply should take into account changes in Atlantic sources (Holt et al., 2012) as well as land-based sources (Painting et al., 2013, their Fig. 4). When considering multiple stressors like acidification, climate change, nutrient supply, and fishing pressure the interactions of different pressures should be studied using statistical techniques such as the Hedges $d$ method: this was applied in Griffith et al. (2012) with respect to ocean warming, ocean acidification, and fishing pressure in Australian marine waters. They showed that interactions between pressures could lead to less than or more than the additive response of the system: for instance, fishing pressure counteracted negative effects from acidification on benthic invertebrates by relieving predation pressure. Similar results were found in this study, as climate-change-induced increases in biomass were counteracted by acidification impacts, with non-additive response. Together with different impact-level studies like the one presented here, these methods have the potential to provide a good indication of future marine response to known pressures.

\section{Conclusions}

This article has provided a first indication of future trends in fisheries harvests, based on a sensitivity study into impacts from both climatic changes and ocean acidification (abiotic and biotic) effects in an economically important shelf sea. To this end we applied a coupled ecosystem model (simulating the hydrodynamics, nutrient cycling, plankton, benthos, fish, and detritivore biomass) to three hydrodynamically different sites in the North Sea. Results showed high regional variability and an overall shift towards more pelagic-oriented systems (due to temperature-induced increased pelagic recycling and acidification impacts on benthic organisms). Fisheries yield displayed an inclination to increase in large parts of the North Sea due to climate change effects, as reported by Blanchard et al. (2012). However, the strength of ocean acidification impacts on both the abiotic and biotic level has the potential to severely mediate this positive impact on fisheries harvest for permanently mixed areas.

The three sites also showed local responses depending on the governing hydrodynamic regime and relative importance of the benthic system:

- Seasonally stratified areas: acidification impacts were of the same order of magnitude as climatic impacts, with indirect and direct acidification effects exhibiting opposing trends. Fisheries yield indicated a positive trend, with both stressors contributing to increased yields which mainly occurred in winter and spring.

- Transitional areas: ocean acidification impacts dominated over climatic effects, reflecting the large benthic system at this site and its importance in transporting carbon to higher trophic levels. Fisheries were predicted to be negatively impacted, mainly due to ocean acidification impacts at species level (due to the relatively large importance of the benthic system). Fish yield under the projected circumstances was predicted to decline, particularly in winter months.

- Well-mixed areas: climatic impacts were of the same order of magnitude as acidification impacts, with a dominant acidification impact on detritivore levels. Increases in fisheries yield were predicted due to more pelagic recycling and increased primary production, but any quantitative change will depend heavily on the strength of acidification effects on both the abiotic environment and the species level (assuming no change in nutrient supply). Changes in fish yield were equally distributed over the seasons when impacts were of similar strength, with predicted reduced yield in winter and increased yield in summer. 
Acknowledgements. This work was enabled through Cefas Seedcorn project DP282 and Defra project ME5216: Impacts from climate change on ocean acidification on Fisheries and Marine Biodiversity (IFMA). Data used for validation were obtained from Jennings et al. (2002) and Maxwell and Jennings (2006). The authors want to thank Laurent Bopp (editor), Beth Fulton (reviewer), the anonymous reviewer, and Jean-Pierre Gattuso for the constructive and knowledgeable feedback received. As always, the manuscript is the better for it.

Edited by: L. Bopp

\section{References}

Andersson, A. J. and Mackenzie, F. T.: Revisiting four scientific debates in ocean acidification research, Biogeosciences, 9, 893905, doi:10.5194/bg-9-893-2012, 2012.

Andersson, A. J., Mackenzie, F. T., and Gattuso, J.-P.: Ocean acidification: effects of ocean acidification on benthic processes, organisms and ecosystems, 122-153, Oxford University Press, Oxford, 2011

Artioli, Y., Blackford, J. C., Nondal, G., Bellerby, R. G. J., Wakelin, S. L., Holt, J. T., Butenschön, M., and Allen, J. I.: Heterogeneity of impacts of high $\mathrm{CO}_{2}$ on the North Western European Shelf, Biogeosciences, 11, 601-612, doi:10.5194/bg-11601-2014, 2014.

Baretta, J. W., Ebenhöh, W., and Ruardij, P.: The European Regional Seas Ecosystem Model: a complex marine ecosystem model, J. Mar. Res., 33, 233-246, 1995.

Beman, J. M., Chow, C.-E., King, A. L., Feng, Y., Fuhrman, J. A., Andersson, A., Bates, N. R., Popp, B. N., and Hutchins, D. A.: Global declines in oceanic nitrification rates as a consequence of ocean acidification, P. Natl. Acad. Sci. USA, 108, 208-213, doi:10.1073/pnas.1011053108, 2011.

Blanchard, J. L., Jennings, S., Law, R., Castle, M. D., McCloghrie, P., Rochet, M.-J., and Benoît, E.: How does abundance scale with body size in coupled size-structured food webs?, J. Anim. Ecol., 78, 270-280, doi:10.1111/j.13652656.2008.01466.x, 2009.

Blanchard, J. L., Law, R., Castle, M. D., and Jennings, S.: Coupled energy pathways and the resilience of size-structured food webs, Theor. Ecology, 4, 289-300, doi:10.1007/s12080-010-0078-9, 2010.

Blanchard, J. L., Jennings, S., Holmes, R., Harle, J., Merino, G., Allen, J. I., Holt, J., Dulvy, N. K., and Barange, M.: Potential consequences of climate change for primary production and fish production in large marine ecosystems, Philos. T. Roy. Soc. B, 367, 2979-2989, doi:10.1098/rstb.2012.0231, 2012.

Burchard, H., Bolding, K., and Villareal, M. R.: GOTM - a general ocean turbulence model. Theory, applications and test cases, Joint Research Centre (Ispra), Tech. Rep. EUR 18745 EN, European Commission, 1999.

Cheung, W. W. L., Lam, V. W. Y., Sarmiento, J. L., Kearney, K., Watson, R., Zeller, D., and Pauly, D.: Large-scale redistribution of maximum fisheries catch potential in the global ocean under climate change, Glob. Change Biol., 16, 24-35, doi:10.1111/j.1365-2486.2009.01995.x, 2010.
Doney, S. C., Fabry, V. J., Feely, R. A., and Kleypas, J. A.: Ocean acidification: the other $\mathrm{CO}_{2}$ problem, Ann. Rev. Mar. Sci., 1, 169-192, doi:10.1146/annurev.marine.010908.163834, 2009.

Ebenhöh, W., Baretta-Bekker, J. G., and Baretta, J. W.: The primary production module in the marine ecosystem model ERSEM II, with emphasis on the light forcing, J. Sea Res., 38, 173-193, 1997.

Fabry, V. J., Seibel, B. A., Feely, R. A., and Orr, J. C.: Impacts of ocean acidification on marine fauna and ecosystem processes, ICES J. Mar. Sci., 65, 414-432, doi:10.1093/icesjms/fsn048, 2008.

Gattuso, J. P., Bijma, J., Gehlen, M., Riebesell, U., and Turley, C.: Ocean acidification: knowns, unknowns and perspectives, Oxford University Press, Oxford, 291-313, 2011.

Griffith, G. P., Fulton, E. A., Gorton, R., and Richardson, A. J.: Predicting Interactions among Fishing, Ocean Warming, and Ocean Acidification in a Marine System with Whole-Ecosystem Models, Conserv. Biol., 26, 1145-1152, doi:10.1111/j.15231739.2012.01937.x, 2012.

Holt, J., Hughes, S., Hopkins, J., Wakelin, S. L., Holliday, N .P., Dye, S., Gonzalez-Pola, C., Hjollo, S. S., Mork. K. A., Nolan, G., Proctor, R., Read, J., Shammon, T., Sherwin, T., Smyth, T., Tattersall, G., Ward, B., and Wiltshire, K. H.: Multi-decadal variability and trends in the temperature of the northwest European continental shelf: a model-data synthesis, Progr. Oceangr., 109, 96-117, doi:10.1016/j.pocean.2012.08.001, 2012.

Huesemann, M. H., Skillman, A. D., and Crecelius, E. A.: The inhibition of marine nitrification by ocean disposal of carbon dioxide, Mar. Pollut. Bull., 44, 142-148, doi:10.1016/S0025326X(01)00194-1, 2002.

Hutchins, D. A., Mulholland, M., and Fu, F. X.: Nutrient cycles and marine microbes in a $\mathrm{CO}_{2}$-enriched ocean, Oceanography, 22, 128-145, 2009.

ICES: Report of the study group on multispecies assessment in the North Sea (SGMSNS), ICES headquarters, Copenhagen, Denmark, D06, 163 pp., 2005.

Jennings, S., Warr, K. J., and Mackinson, S.: Use of size-based production and stable isotope analyses to predict trophic transfer efficiencies and predator-prey body mass ratios in food webs, Mar. Ecol.-Prog. Ser., 240, 11-20, doi:10.3354/meps240011, 2002.

Jolliff, J. K., Kindle, J. C., Shulman, I., Penta, B., Friedrichs, M. A., Helber, R., and Arnone, R. A.: Summary diagrams for coupled hydrodynamic-ecosystem model skill assessment, J. Marine Syst., 76, 64-82, doi:10.1016/j.jmarsys.2008.05.014, 2009.

Kerr, S. R.: Theory of size distribution in ecological communities, J. Fish Res. Board Can., 31, 1859-1862, doi:10.1139/f74-241, 1974.

Kerr, S. R. and Dickie, L. M.: The biomass spectrum: a predatorprey theory of aquatic production, Columbia University Press, New York, 2001.

Kroeker, K. J., Kordas, R. L., Crim, R. N., and Singh, G. G.: Meta-analysis reveals negative yet variable effects of ocean acidification on marine organisms, Ecol. Lett., 13, 1419-1434, doi:10.1111/j.1461-0248.2010.01518.x, 2010.

Kroeker, K. J., Kordas, R. L., Crim, R. N., Hendriks, I. E., Ramajo, L., Singh, G. S., Duarte, C. M. and Gattuso, J.-P.: Impacts of ocean acidification on marine organisms: quantifying sensitivities and interaction with warming, Glob. Change Biol., 19, 18841896, doi:10.1111/gcb.12179, 2013. 
Le Quesne, W. J. F. and Pinnegar, J. K.: The potential impacts of ocean acidification: scaling from physiology to fisheries, Fish Fish., 13, 333-344, doi:10.1111/j.1467-2979.2011.00423.x, 2012.

Liu, J., Weinbauer, M. G., Maier, C., Dai, M., and Gattuso, J. P.: Effect of ocean acidification on microbial diversity and on microbedriven biogeochemistry and ecosystem functioning, Aquat. Microb. Ecol., 61, 291-305, doi:10.3354/ame01446, 2010.

Maxwell, T. A. D. and Jennings, S.: Predicting abundance-body size relationships in functional and taxonomic subsets of food webs, Oecologia, 150, 282-290, doi:10.1007/s00442-006-05202, 2006.

Met Office, H. C.: HadRM3-PPE-UK, available at BADC: http://catalogue.ceda.ac.uk/uuid/ f9c7d70b0e6d4c31c067e75ab67cb3cc (last access: 25 June 2015), 2008.

Murphy, J. M., Booth, B. B. B., Collins, M., Harris, G. R., Sexton, D. M. H., and Webb, M. J.: A methodology for probalistic predictions of regional climate change from perturbed physics emsembles, Philos. T. Roy. Soc. A, 365, 1993-2028, doi:10.1098/rsta.2007.2077, 2007.

Painting, S., Foden, J., Forster, R., van der Molen, J., Aldridge, J. N., Best, M., Jonas, P., Hydes, D., Walsham, P., Webster, L., Gubbins, M., Heath, M., McGovern, E., Vincent, C., Gowen, R., and O'Boyle, S.: Impacts of climate change on nutrient enrichment, Marine Climate Change Impacts Partnership Science Review, Lowestoft, UK, 219-235, doi:10.14465/2013.arc23.219235, 2013.

Ries, J. B., Cohen, A. L., and McCorkle, D. C.: Marine calcifiers exhibit mixed responses to $\mathrm{CO} 2$-induced ocean acidification, $\mathrm{Ge}$ ology, 37, 1131-1134, doi:10.1130/G30210A.1, 2009.

Ruardij, P. and Raaphorst, W.: Benthic nutrient regeneration in the ERSEM-BFM ecosystem model of the North Sea, J. Sea Res., 33, 453-483, doi:10.1016/0077-7579(95)90057-8, 1995.

Ruardij, P., Van Haren, H., and Ridderinkhof, H.: The impacts of thermal stratification on phytoplankton and nutrient dynamics in shelf seas: a model study, J. Sea Res., 38, 311-331, doi:10.1016/S1385-1101(97)00042-7, 1997.

Ruardij, P., Veldhuis, M. J. W., and Brussard, C. P. D.: Modeling the bloom dynamics of the polymorphic phytoplankter Phaeocystis globosa: impact of grazers and viruses, Harmful Algae, 4, 941963, doi:10.1016/j.hal.2004.12.011, 2005.
Sheldon, R. W., Sutcliffe Jr., W. H., and Paranjape, M. A.: Structure of pelagic food chain and relationship between plankton and fish production, J. Fish. Res. Board Can., 34, 2344-2355, doi:10.1139/f77-314, 1977.

Skogen, M. D., Olsen, A., Yngve Børsheim, K., Britt Sandø, A., and Skelvan, I.: Modelling ocean acidification in the Nordic and Barents Seas in present and future climate, J. Marine Syst., 131, 10-20, doi:10.1016/j.jmarsys.2013.10.005, 2014.

Van der Molen, J., Aldridge, J. N., Coughlan, C., Parker, E. R., Stephens, D., and Ruardij, P.: Modelling marine ecosystem response to climate change and trawling in the North Sea, Biogeochemistry, 113, 1-24, doi:10.1007/s10533-012-9763-7, 2013.

Van der Molen, J., Smith, H. C. M., Lepper, P., Limpenney, S., and Rees, J.: Predicting the large-scale consequences of offshore wind turbine array development on a North Sea ecosystem, Cont. Shelf Res., 85, 60-72, doi:10.1016/j.csr.2014.05.018, 2014.

van Leeuwen, S. M., van der Molen, J., Ruardij, P., Fernand, L., and Jickells, T.: Modelling the contribution of Deep Chlorophyll Maxima to annual primary production in the North Sea, Biogeochemistry, 113, 137-152, doi:10.1007/s10533-012-97045, 2013.

van Leeuwen, S. M., Tett, P., Mills, D. K., and van der Molen, J.: Stratified and non-stratified areas in the North Sea: long-term variability and biological and policy implications, J. Geophys. Res.-Oceans, 120, 4670-4686, doi:10.1002/2014JC010485, 2015.

Vichi, M., May, W., and Navarra, A.: Response of a complex ecosystem model of the northern Adriatic Sea to a regional climate change scenario, Clim. Res., 24, 141-158, doi:10.3354/cr024141, 2003.

Vichi, M., Ruardij, P., and Baretta, J. W.: Link or sink: a modelling interpretation of the open Baltic biogeochemistry, Biogeosciences, 1, 79-100, doi:10.5194/bg-1-79-2004, 2004.

Vichi, M., Pinardi, N., and Masina, S.: A generalized model of pelagic biogeochemistry for the global ocean ecosystem. Part I: Theory, J. Marine Syst., 64, 89-109, doi:10.1016/j.jmarsys.2006.03.006, 2007.

Wicks, L. and Roberts, J. M.: Benthic invertebrates in a high- $\mathrm{CO}_{2}$ world, Oceanogr. Mar. Biol., 50, 127-188, doi:10.1201/b121574, 2012. 